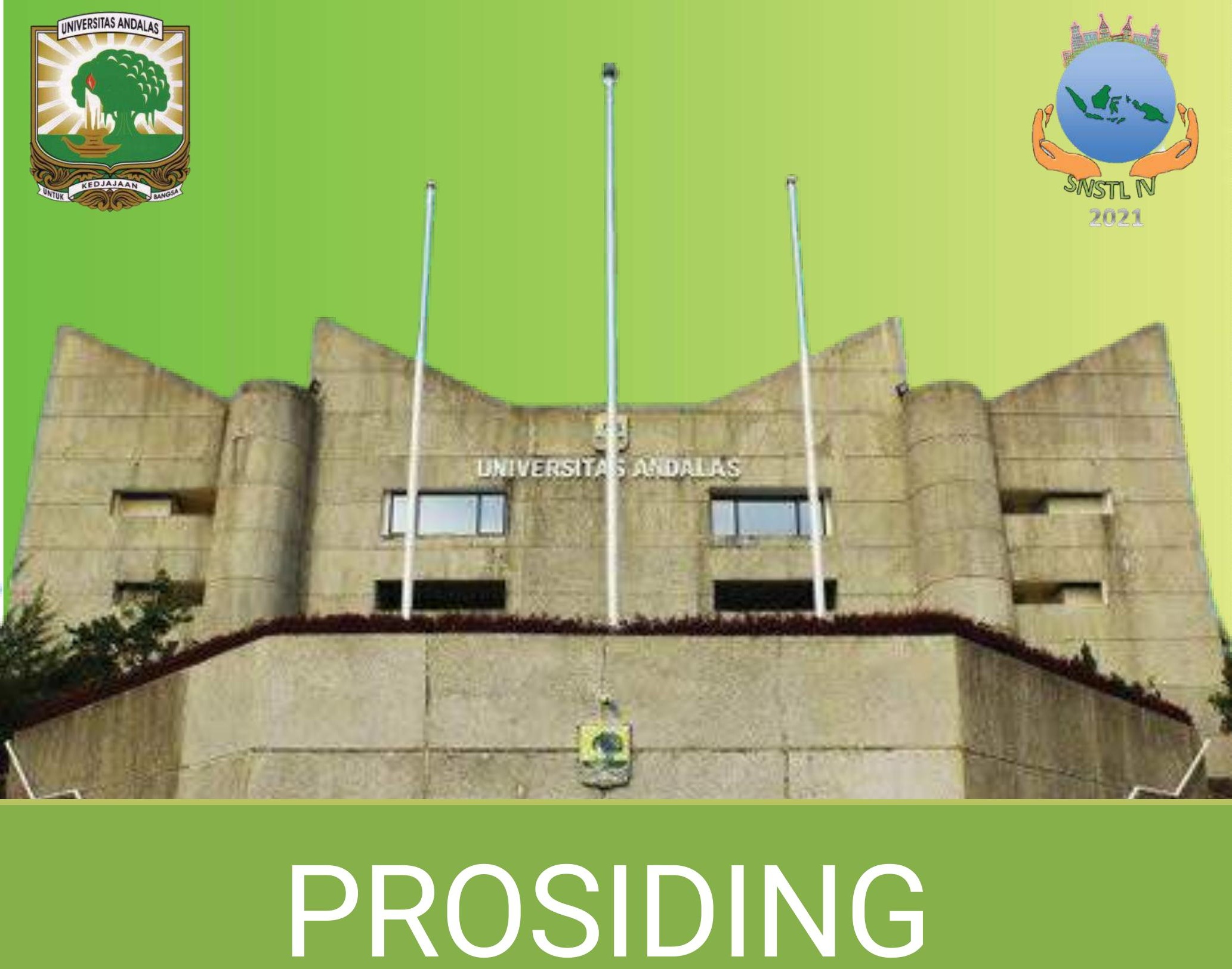

Seminar Nasional Sains dan Teknologi Lingkungan IV Convention Hall Unand, 23 September 2021

"Inovasi Sains dan Teknologi Lingkungan untuk mendukung Sustainable Development Goals"

Prosiding online:

hhtp://conference.ft.unand.ac.id/ index.php/snstl/snstl4

ISSN (Print) :2356-4938 ISSN (Online) :2541-3880 


\section{DEWAN REDAKSI}

Prosiding Seminar Nasional Sains dan Teknologi Lingkungan

\section{Sekretariat:}

Jurusan Teknik Lingkungan, Fakultas Teknik

Universitas Andalas, Padang

Kampus Unand Limau Manis Padang 25163

Email: snstl@eng.unand.ac.id

\section{Pelindung:}

Prof. Ikhwana Elfitri, $\mathrm{PhD}$

\section{Penanggung jawab:}

Rizki Aziz, PhD

\section{Ketua Panitia:}

Dr. Eng Alqadri Asri Putra

\section{Reviewer}

Prof. Vera Surtia Bachtiar, Ph.D

Dr. Puti Sri Komala

Dr. Fadjar Goembira

Dr. Eng Shinta Indah

Rizki Aziz, Ph.D

Dr. Eng Denny Helard

Dr.Eng Zulkarnaini

Dr. Eng Slamet Raharjo

Yenni Ruslinda, MT

Budhi Primasari, MSc

\section{Penyunting Pelaksana:}

Budhi Primasari, M.Sc (Koordinator)

Tivany Edwin, M.Eng

Iqbal Putra

Ghofar Mulki

Citra Dara Zulvia K.

Reski Anggika

Meuthia Melliaroza

Ayu Ardhinni

Agung Prajimeko 
Online pada laman http://conference.ft.unand.ac.id/index.php/snstl/snstl4

Prosiding Seminar Nasional Sains dan Teknologi Lingkungan (SNSTL) IV 2021

\title{
Kinerja Filter Portabel Tepat Guna dalam Mereduksi Kekeruhan Air Banjir untuk Sanitasi atau MCK
}

\author{
Gede H Cahyana ${ }^{a}$, Teddy Gunawan ${ }^{a}$ Tri Mulyani ${ }^{a}$
}

${ }^{a}$ Teknik Lingkungan Universitas Kebangsaan, Jln. Ters. Halimun No. 37, Bandung, 40263, Indonesia

E-mail: ghcahyana@gmail.com

\begin{abstract}
ABSTRAK
Saat banjir warga kesulitan mendapatkan air bersih untuk sanitasi atau jamban. Ada banyak air banjir tetapi sangat keruh. Filter air yang tersedia membutuhkan listrik tetapi listriknya padam saat banjir. Studi ini mengevaluasi kinerja filter portabel air banjir yang dioperasikan secara manual. Baku mutu Permenkes No. 32/2017 digunakan sebagai acuan. Filter air banjir diberi tekanan $0,025 \mathrm{kgf} / \mathrm{cm}^{2}$ dan $0,051 \mathrm{kgf} / \mathrm{cm}^{2}$. Media filter berbahan lokal seperti kerikil, pasir silika, antrasit, spons. Hasil penelitian menunjukkan bahwa tekanan $0,025 \mathrm{kgf} / \mathrm{cm}^{2}$ mampu menurunkan kekeruhan dari 220 NTU menjadi 20,17 NTU dengan efisiensi 90,83\%. Pada 0,051 kgf/ $\mathrm{cm}^{2}$ filter mampu menurunkan kekeruhan dari 220 NTU menjadi 29,67 NTU dengan efisiensi 86,52\%. Variasi tekanan yang diterapkan pada filter berpengaruh pada kualitas filtrat. Filter bertekanan $0,025 \mathrm{kgf} / \mathrm{cm}^{2}$ memiliki kinerja optimal dan menghasilkan 100 150 liter sebelum tersumbat. Filter ini masih perlu dikaji terkait dengan kekuatan fisik filter, jenis dan komposisi media, portabilitas dan volume air yang dihasilkan. Filter air banjir ini akan menjadi solusi alternatif untuk daerah yang sering banjir tetapi tidak ada listrik atau listrik padam saat banjir.
\end{abstract}

Kata kunci : banjir, filter potable, tekanan, sanitasi, turbiditas

\begin{abstract}
During flood people had difficulties in obtaining clean water for sanitation or toilet. There was plenty of flood water but highly turbid. The water filter required electricity but its power outaged during flood. This study evaluated the performance of a manually operated flood water portable filter. The quality standard of Permenkes No. 32/2017 was used as a reference. The flood water filter was pressurized by $0.025 \mathrm{kgf} / \mathrm{cm}^{2}$ and $0.051 \mathrm{kgf} / \mathrm{cm}^{2}$. The filter media were local materials such as gravel, silica sand, anthracite, sponge. The results showed that pressure $0.025 \mathrm{kgf} / \mathrm{cm}^{2}$ was able to reduce turbidity from $220 \mathrm{NTU}$ to $20.17 \mathrm{NTU}$ with efficiency $90.83 \%$. At $0.051 \mathrm{~kg} / \mathrm{cm}^{2}$ the filter was able to reduce turbidity from $220 \mathrm{NTU}$ to $29.67 \mathrm{NTU}$ with efficiency $86.52 \%$. The results showed that the pressure variation significantly affects the filtrate quality. The filter with pressure $0.025 \mathrm{kgf} / \mathrm{cm}^{2}$ could be applied for optimal filtration and produced 100 - 150 liters before clogging. This filter still needs to be studied related to physical strength, type and composition of media, portability and volume of water produced. This flood water filter will be an alternative solution for areas that often flood but no electricity or the power outage during flood.
\end{abstract}

Keywords : flood, portable filter, pressure, sanitation, turbidity

\section{PENDAHULUAN}

Merujuk pada Bakornas di dalam riset Shalihat (2015) definisi banjir adalah limpasan air yang melebihi tinggi muka air normal sehingga melimpas dari sungai yang menyebabkan genangan di lahan rendah. Radianta di dalam penelitian Pandiangan (2018) menulis bahwa pada saat banjir kebutuhan air bersih orang 
yang terkena bencana ini bisa mencapai 60-100 liter per orang per hari. Pada kondisi normal hanya 10-15 liter per orang per hari. Kuantitas ini dinyatakan sudah cukup.

Pada saat banjir biasanya pasokan air dari PDAM terhenti kaena pompa distribusi airnya terendam banjir atau aliran listriknya padam atau pasokan air bakunya terputus. Pada saat yang sama air sumur gali juga tercemari oleh air banjir, baik karena rembesan maupun karena limpasan langsung air banjir yang tinggi muka airnya. Kualitas air sumur sudah seperti air banjir. Tersedia berlimpah air banjir yang kualitasnya tidak layak untuk sanitasi atau MCK. Air untuk sanitasi atau MCK selalu dibutuhkan kapanpun dan di manapun. Orang harus tetap bebersih setelah buang air kecil dan air besar, juga mandi dan kebutuhan air untuk wudhu. Dengan latar belakang kondisi tersebut maka perlu disediakan alat pengolah air banjir yang tepat guna untuk mengatasi kelangkaan air bersih di daerah yang dilanda banjir. Karena listrik biasanya padam pada saat banjir atau banjir terjadi di daerah yang belum ada listrik seperti di perdesaan maka perlu dibuat alat pengolah air banjir menjadi air bersih secara tepat guna yang tidak membutuhkan pasokan listrik. Air banjir memiliki karakteristik kekeruhan (turbidity) yang cukup tinggi, bisa mencapai 200-300 NTU.

Kekeruhan air disebabkan oleh terutama zat padat tersuspensi dan koloid, bisa berasal dari zat anorganik dan organik yang dilewati oleh air. Air yang tinggi kekeruhannya akan sulit didisinfeksi karena mikroba atau bakteri terhalang oleh zat padat tersuspensi dan koloid tersebut sehingga bakteri patogen sulit dibasmi dan bahkan terus berkembang biak. Tentu air yang keruh ini berbahaya bagi kesehatan masyarakat pengguna air banjir, misalnya digunakan untuk wudhu, mandi, sikat gigi, atau mencuci sayur.

Dari uraian masalah di atas maka penelitian ini bermaksud memberikan opsi alat penjernih air banjir. Tujuannya adalah merancang bentuk alat, kemudian membuat beberapa alat dan mengujinya dengan memberikan umpan air banjir untuk diolah. Kualitas air olahan alat ini diharapkan memenuhi persyaratan baku mutu Permenkes No. 32/2017. Alat yang digunakan untuk mengolah air banjir ini adalah filter. Filter ini diupayakan bisa dipindah-pindahkan atau dibawa dengan mudah. Filter ini adalah modifikasi filter konvensional yang biasa digunakan di PDAM, yaitu menggunakan media pasir dengan tambahan media lainnya.

Aliran air filter PDAM biasanya ke bawah atau downflow tetapi alat ini didesain dengan aliran upflow. Aliran ke atas ini membutuhkan energi agar airnya bisa mengalir. Sumber energinya adalah tenaga manusia sehingga tetap bisa digunakan pada saat listrik padam atau belum ada pasokan energi listrik. Untuk meningkatkan kualitas air olahannya (filtrat) maka alat filter ini juga diisi dengan antrasit di bagian atas. Modifikasi media filter (filter bed) bisa dengan berbagai bahan atau zat yang tersedia di lokasi banjir dengan satu syarat, yaitu media harus berbentuk butiran kecil seperti pasir dan kuat atau tidak mudah pecah. Apabila getas maka filter akan cepat tersumbat.

Dengan demikian dapat diringkaskan bahwa tujuan penelitian ini adalah (a) Membuat desain filter portabel tepat guna yang efektif dalam mengurangi kekeruhan air banjir; (b) Mengetahui kinerja filter, baik hal-hal positif maupun negatifnya dalam mengolah air banjir; (c) Mengetahui pengaruh tekanan (dalam hal ini adalah berat benda sebagai beban yang diasumsikan sebagai tekanan dan gaya tekan tangan manusia) terhadap keefektifan filter dalam menurunkan kekeruhan air banjir.

\section{METODOLOGI}

Penelitan ini bertujuan untuk merancang, merakit dan menguji keefektifan desain filter portabel tepat guna dalam menurunkan kekeruhan air banjir. Penelitian ini bersifat kuasi eksperimen. Menurut Arikunto di dalam penelitian Jayanti (2018), ada tiga model pada kuasi eksperimen, yaitu one - shot case study, pretest-post-test group dan static group comparison. Teknik yang digunakan untuk mengumpulkan data penelitian ini adalah dengan metode pre-test post-test group terhadap sampel air yang diteliti serta diukur dengan turbidimeter.

Variabel penelitian ini terdiri atas tiga variabel, yaitu variabel independen, variabel dependen dan variabel pengganggu. Analisis data pada penelitian ini dimaksudkan untuk mengetahui nilai keefektifan filtrasi alat filter dalam menurunkan kekeruhan dan menguji ada tidaknya pengaruh tekanan pada filter terhadap keefektifan filtrasi oleh filter penurun kekeruhan. Adapun perhitungan efisiensi filter adalah sebagai berikut:

$\%$ Efisiensi $=\mathrm{x} 100 \%$ 
Untuk mengurangi kekeruhan air banjir mka peneliti merancang, merakit dan menguji alat filter portabel tepat guna (disingkat FPG) dengan tekanan dari tenaga manusia. Untuk mengetahui besar-kecilnya tekanan tersebut maka digunakan benda dengan berat tertentu yang diletakkan di atas tuas (pompa penekan) filter. Filter ini mengalirkan air dari bawah ke atas dan air baku ini difiltrasi oleh media pasir silika, kerikil, antrasit dan spons.

Penelitian ini dilaksanakan dalam tiga tahap perlakuan. Yang pertama adalah menguji sampel air sebelum filtrasi, yang kedua adalah menguji keefektifan filter dengan mengukur kekeruhan air banjir sebelum dan sesudah diolah oleh filter yang diberi beban atau benda seberat $2 \mathrm{~kg}$. Yang ketiga adalah menguji keefektifan filter dengan mengukur kekeruhan air banjir sebelum dan sesudah diolah oleh filter yang diberi beban seberat $4 \mathrm{~kg}$. Berat tersebut adalah asumsi berat yang akan diteria oleh filter pada saat ditekan oleh orang remaja atau dewasa. Selajutnya kualitas air olahan filter ini dirujuk pada Permenkes No. 32 tahun 2017 yang menetapkan bahwa maksimum nilai kekeruhan untuk air higiene sanitasi adalah 25 NTU.

\section{HASIL DAN PEMBAHASAN}

Hasil perancangan filter diberikan dalam foto dan gambar seperti tampak di sini. Yang ditampilkan adalah hasil trial-error terakhir dan digunakan sebagai objek penelitian. Filter desain terakhir inilah yang diteliti dan hasilnya ditabelkan berikut ini. Tabel berisi data kekeruhan awal, kekeruhan akhir, dan efisiensi reduksi yang mampu dicapai oleh filter.

\section{Tabel}

Hasil pembebanan, yaitu efisiensi serial percobaan pada eksperimen pertama ditabelkan pada Tabel 1. Secara garis besar bisa dilihat bahwa mayoritas efisiensi di atas $90 \%$.

Tabel 1. Hasil Pengukuran Konsentrasi Kekeruhan FPG 1

\begin{tabular}{|c|c|c|c|c|c|}
\hline \multirow[b]{2}{*}{ Percobaan } & \multirow[b]{2}{*}{$\begin{array}{c}\text { Pengulangan } \\
\text { Pengukuran }\end{array}$} & \multicolumn{2}{|c|}{ FPG.1 } & \multirow{2}{*}{$\begin{array}{c}\text { Persentase } \\
\text { Pengurangan } \\
(\%)\end{array}$} & \multirow{2}{*}{$\begin{array}{c}\text { Standar } \\
\text { Permenk } \\
\text { es } \\
\text { (NTU) }\end{array}$} \\
\hline & & $\begin{array}{l}\text { Influent } \\
\text { (NTU) }\end{array}$ & $\begin{array}{l}\text { Effluent } \\
\text { (NTU) }\end{array}$ & & \\
\hline \multirow{2}{*}{ Percobaan 1} & Pengulangan 1 & 220 & 31 & 85,91 & \multirow{7}{*}{25} \\
\hline & Pengulangan 2 & 220 & 18 & 91,82 & \\
\hline \multirow{2}{*}{ Percobaan 2} & Pengulangan 1 & 220 & 18 & 91,82 & \\
\hline & Pengulangan 2 & 220 & 19 & 91,36 & \\
\hline \multirow{2}{*}{ Percobaan 3} & Pengulangan 1 & 220 & 16 & 92,73 & \\
\hline & Pengulangan 2 & 220 & 19 & 91,36 & \\
\hline \multicolumn{2}{|c|}{ Rata-rata } & 220 & 20,17 & 90,83 & \\
\hline
\end{tabular}

Hasil pembebanan, yaitu efisiensi serial percobaan pada eksperimen kedua ditabelkan pada Tabel 2. Efisiensi pada eksperimen kedua ini lebih kecil dari $90 \%$ tetapi hampir semua di atas $85 \%$.

Tabel 2. Hasil Pengukuran Konsentrasi Kekeruhan FPG 2

\begin{tabular}{|c|c|c|c|c|c|}
\hline \multirow[b]{2}{*}{ Percobaan } & \multirow{2}{*}{$\begin{array}{l}\text { Pengulangan } \\
\text { Pengukuran }\end{array}$} & \multicolumn{2}{|c|}{ FPG.2 } & \multirow{2}{*}{$\begin{array}{c}\text { Persentase } \\
\text { Pengurangan } \\
(\%)\end{array}$} & \multirow{2}{*}{$\begin{array}{c}\text { Standar } \\
\text { Permenkes } \\
\text { (NTU) }\end{array}$} \\
\hline & & $\begin{array}{c}\text { Influent } \\
\text { (NTU) }\end{array}$ & $\begin{array}{l}\text { Effluent } \\
\text { (NTU) }\end{array}$ & & \\
\hline \multirow{2}{*}{ Percobaan 1} & Pengulangan 1 & 220 & 34 & 84,55 & \multirow{7}{*}{25} \\
\hline & Pengulangan 2 & 220 & 29 & 86,82 & \\
\hline \multirow{2}{*}{ Percobaan 2} & Pengulangan 1 & 220 & 33 & 85,00 & \\
\hline & Pengulangan 2 & 220 & 27 & 87,73 & \\
\hline \multirow{2}{*}{ Percobaan 3} & Pengulangan 1 & 220 & 24 & 89,09 & \\
\hline & Pengulangan 2 & 220 & 31 & 85,91 & \\
\hline \multicolumn{2}{|c|}{ Rata-rata } & 220 & 29,67 & 86,52 & \\
\hline
\end{tabular}


Tabel 3. Kekeruhan Setelah Perlakuan pada FPG.1 dan FPG.2

\begin{tabular}{|c|c|c|c|c|c|}
\hline \multirow[b]{2}{*}{ Percobaan } & \multirow{2}{*}{$\begin{array}{l}\text { Pengulangan } \\
\text { Pengukuran }\end{array}$} & \multicolumn{2}{|c|}{ FPG.2 } & \multirow{2}{*}{$\begin{array}{c}\text { Persentase } \\
\text { Pengurangan } \\
(\%)\end{array}$} & \multirow{2}{*}{$\begin{array}{c}\text { Standar } \\
\text { Permenkes } \\
\text { (NTU) }\end{array}$} \\
\hline & & $\begin{array}{l}\text { Influent } \\
\text { (NTU) }\end{array}$ & $\begin{array}{l}\text { Effluent } \\
\text { (NTU) }\end{array}$ & & \\
\hline \multirow{2}{*}{ Percobaan 1} & Pengulangan 1 & 220 & 34 & 84,55 & \multirow{7}{*}{25} \\
\hline & Pengulangan 2 & 220 & 29 & 86,82 & \\
\hline \multirow{2}{*}{ Percobaan 2} & Pengulangan 1 & 220 & 33 & 85,00 & \\
\hline & Pengulangan 2 & 220 & 27 & 87,73 & \\
\hline \multirow{2}{*}{ Percobaan 3} & Pengulangan 1 & 220 & 24 & 89,09 & \\
\hline & Pengulangan 2 & 220 & 31 & 85,91 & \\
\hline \multicolumn{2}{|c|}{ Rata-rata } & 220 & 29,67 & 86,52 & \\
\hline
\end{tabular}

Hasil pemeriksaan kekeruhan air filtrat pada filter yang diberi tekanan $0,025 \mathrm{kgf} / \mathrm{cm}^{2}$ diperolah efisiensi penurunan kekeruhan $90,83 \%$. Kinerja filter yang diberi tekanan $0,050 \mathrm{kgf} / \mathrm{cm}^{2}$ adalah $86,52 \%$.

Dengan mengacu pada hasil tersebut maka diperoleh informasi bahwa filter portabel tepat guna bertekanan $0,025 \mathrm{kgf} / \mathrm{cm}^{2}$ memiliki kinerja lebih tinggi dalam mereduksi kekeruhan air banjir sehingga memenuhi syarat baku mutu untuk air sanitasi atau MCK

\section{Gambar}

Gambar 1 adalah hasil perancangan filter dari beberapa desain yang dibuat dan dianalisis. Filter terdiri atas dua tabung atau ruang (chamber), yaitu ruang air umpan (feed water) dan ruang filter. Di dalam ruang umpan diisi tuas dan klep untuk menekan air banjir agar mengalir ke ruang filter. Di ruang filter diisi media atau filter bed.

Pada Gambar 2 ditampilkan gambar tiga dimensi filter dan foto filter dengan tuas pendorong yang dilengkapi dengan klep di bagian bawah. Outlet berada di bagian atas filter. Dalam foto ini tidak diperlihatkan rangka dudukan filter agar stabil berdiri.

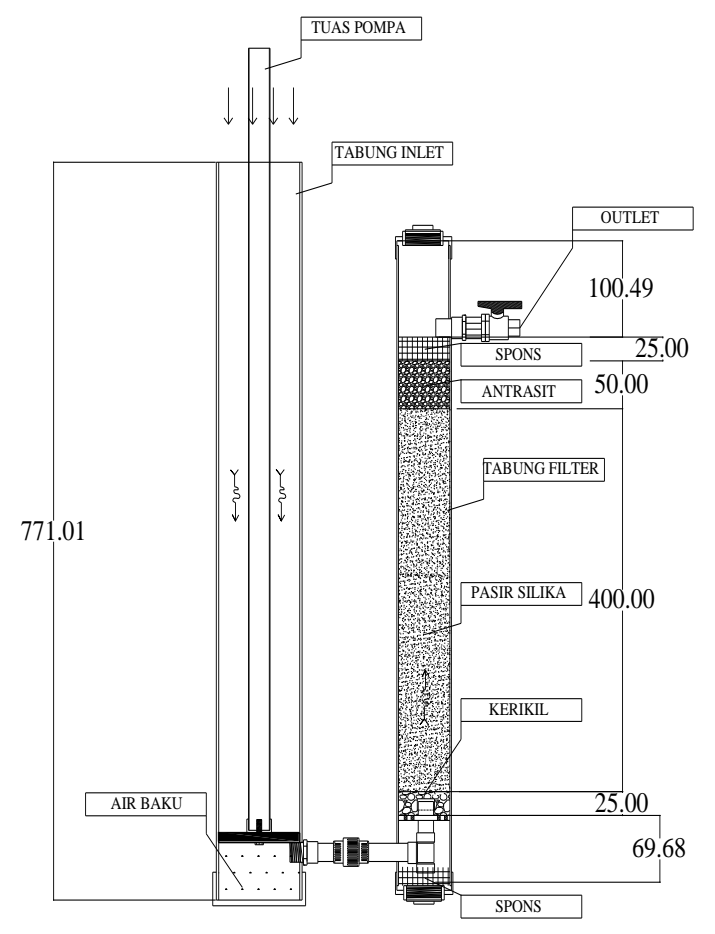

Gambar 1. Desain Filter Portabel Tepat Guna 


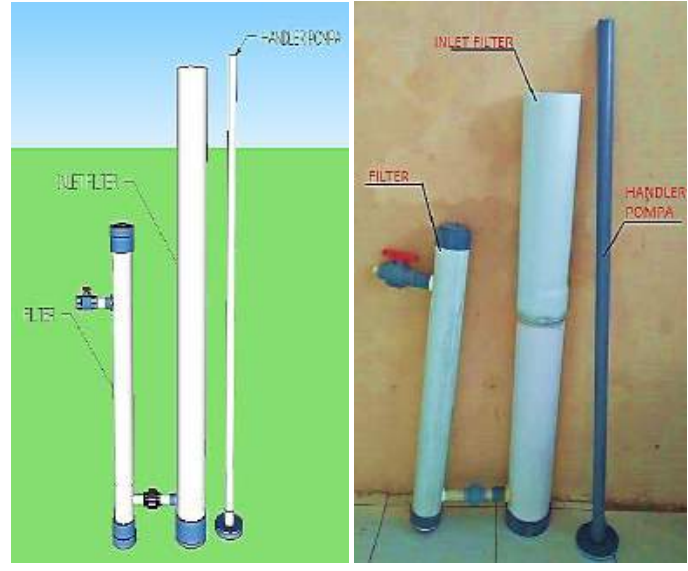

Gambar 2. Desain Efektif Filter Portabel

\section{KESIMPULAN}

Desain filter portabel tepat guna pengolah air banjir menjadi air bersih untuk keperluan sanitasi dan MCK dengan media pasir silika, antrasit, kerikil dan spons dibuat untuk menerima tekanan manual dengan aliran upflow efektif menurunkan kekeruhan air banjir. Bagian yang masih perlu dikembangkan dalam filter air banjir ini adalah (a) Volume air olahan filter relatif sedikit. (b) Filter sensitif pada tekanan besar (c) Filter belum kukuh atau kuat. Tekanan $0,025 \mathrm{kgf} / \mathrm{cm}^{2}$ mampu menurunkan kekeruhan dari 220 NTU menjadi 20,17 NTU, efisiensi 90,83\%. Tekanan $0,051 \mathrm{kgf} / \mathrm{cm}^{2}$ mampu menurunkan kekeruhan dari 220 menjadi 29,67 NTU, efisiensi $86,52 \%$. E. Filter portabel air banjir dengan tekanan $0,025 \mathrm{kgf} / \mathrm{cm}^{2}$ dapat menghasilkan volume air produksi 100-150 liter. Filter ini masih perlu diteliti dalam hal kekuatan, jenis dan susunan media filter. Portabilitas dan volume air poduksinya. Filter berpeluang menjadi alternatif solusi bagi daerah yang sering banjir dan listriknya sering padam.

\section{DAFTAR PUSTAKA}

Pandiangan, K. A. (2018). Perencanaan Dan Perancangan Instalasi Pengolahan Air Bersih Di Kecamatan Pantai Labu Kabupaten Deli Serdang. Sumatera Utara: Tugas Akhir, http://repositori.usu.ac.id/bitstream/handle/ 123456789/9208/120407010.pdf

Jayanti, P. N. (2018). Efektivitas Penggunaan Kombinasi Pasir Kuarsa Dan Batu Zeolit Dalam Penurunan Kadar Besi (Fe) Pada Air Sumur Gali Studi Dilaksanakan Di Jalan Sidakarya Gang Taman Suci, Desa Sidakarya. Thesis, http://repository.poltekkes denpasar.ac.id/144/.pdf

Shalihat, A. K. (2015). Pola Adaptasi Masyarakat di Perumahan Genuk Indah Kota Semarang. Semarang: Skripsi, https://lib.unnes.ac.id/21284/1/3211410026-s.pdf.

Dokumen lembaga

Permenkes RI NO.32 Tahun 2017. (t.thn.). Tentang Standar Baku Mutu Kesehatan Lingkungan Dan Persyaratan Kesehatan Air Untuk Keperluan Higiene Sanitasi,Kolam Renang,Solus Per Aqua,Dan Pemandian Umum. Jakarta: Berita Negara Republik Indonesia Tahun 2017 Nomor 864. 